\title{
Automated Microscopy Techniques on Passively Collected Samples Provide Reliable Quantitative Data on Airborne Pollen
}

\author{
Elena Gottardini ${ }^{1 *}$, Fabiana Cristofolini ${ }^{1}$, Antonella Cristofori ${ }^{1}$, Mario Meier ${ }^{2}$, \\ Juanita Rausch ${ }^{3}$, David Jaramillo Vogel ${ }^{3}$, Benjamin Michen ${ }^{4}$ \\ ${ }^{1}$ Fondazione Edmund Mach, Via E. Mach 1, 38010 S. Michele all'Adige (TN), Italy \\ ${ }^{2}$ FUB, Forschungsstelle für Umweltbeobachtung AG, Alte Jonastrasse 83, 8640 Rapperswil, \\ Switzerland \\ ${ }^{3}$ Particle Vision GmbH, c/o Friup, Annexe 2, passage du Cardinal 11, 1700 Fribourg, Switzerland \\ ${ }^{4}$ passam ag, Laboratory for environmental analysis, Schellenstrasse 44, 8708 Männedorf, \\ Switzerland
}

\section{ABSTRACT}

Data on airborne particles are critical to protecthuman health. Anthropogenic (e.g., soot, and tire and brake wear) as well as biogenic (e.g., pollen and spores) particles are usually monitored by active samplers located in urban environments; thus, very few data are available for remote, mountainous areas. In addition, bioaerosol analysis is time-consuming and skill-intensive. Hence, to avoid the obstacles of active sampling (i.e., the high cost and power consumption) and simplify data analysis, we investigated passive sampling combined with automated analysis as a method for pollen detection. We deployed two Sigma-2 passive samplers for 12 week-long periods during 2018 in San Michele all'Adige, Italy, where airborne pollen has been monitored by a volumetric Hirst-type sampler since 1990. To obtain the morpho-chemical information of single particles, we then analyzed the samples using (i) automated optical microscopy (OM) followed by image analysis based on the particle sizes and grey values, and (ii) automated scanning electron microscopy coupled with energy-dispersive X-ray spectroscopy (SEM/EDX). The automated OM detected bright particles (i.e., from natural sources) in the size range of 20-80 $\mu \mathrm{m}$, which accurately represented the total pollen, and the SEM/EDX filtered the particles by size, shape and chemical composition, which enabled us to identify the likely pollen candidates (the "pollen-like" fraction). Overall, automated analytical techniques can concurrently provide data on airborne anthropogenic, geogenic and biogenic particles, including pollen. Furthermore, passive sampling offers a reliable option for collecting data in aerobiological studies, especially in remote areas, where maintaining active samplers is challenging.

${ }^{*}$ Corresponding Author:

elena.gottardini@fmach.it

\section{Publisher:}

Taiwan Association for Aerosol Research

ISSN: $1680-8584$ print

ISSN: 2071-1409 online

(c) Copyright: The Author's

institution. This is an open access article distributed under the terms of the Creative Commons Attribution License (CC BY 4.0), which permits unrestricted use, distribution, and reproduction in any medium, provided the original author and source are cited.

\section{INTRODUCTION}

Airborne particles of natural and anthropogenic nature are characterized by different size distributions, morphological features and chemical composition. It is important to identify and quantify the different particle fractions since they can have several implications for the ecosystems (Gieré and Querol, 2010), plant and human health (Martorano and Erwin, 2018; Nunez and Moreno, 2020). The routine air quality monitoring, usually carried out by the environmental agencies, generally focuses on $\mathrm{PM}_{10}$, broadly speaking the particles with aerodynamic diameter $\left(\mathrm{d}_{\mathrm{ae}}\right)$ smaller than $10 \mu \mathrm{m}$. This fraction is at most separated in the following size fractions: ultrafine $\left(\mathrm{d}_{\mathrm{ae}}<0.1 \mu \mathrm{m}\right)$, fine $\left(d_{a e}<2.5 \mu \mathrm{m}\right)$ and coarse $\left(2.5<d_{a e}<10 \mu \mathrm{m}\right)$ particles. Within the airborne particulate, a biological fraction is present (Hyde and Mahalov, 2020), mostly represented by pollen and spores with 
sizes ranging approximately between $10 \mu \mathrm{m}$ and $150 \mu \mathrm{m}$ (D'Amato and Spieksma, 1991).

The monitoring of airborne pollen can be realized on the basis of different physical principles, and adopting different techniques and related instruments (Mandrioli et al., 1998). When designing the experimental setup, the choice of the most suitable sampling device depends overall on the study purpose, on the characteristics of the targeted environment and the existence of constraints (e.g., costs, power supply availability). Among the several available options, the active volumetric sampling by means of Hirst-type samplers (Hirst, 1952) is the most adopted by national aerobiological networks around the world (https://www.eaaci.org/19-activities/task-forces/4342pollen-monitoring-stations-of-the-world.html; Butlers et al., 2018), especially in Europe where national networks (e.g., POLLnet [http://www.pollnet.it/default_it.asp], REA [http://www.uco.es/ investiga/grupos/rea/], and MeteoSwiss [https://www.meteoswiss.admin.ch/home/measurementand-forecasting-systems/land-based-stations/pollen-monitoring-network.html]) provide information on pollen concentration in the air to people suffering of allergy. Knowing which species and how many pollen grains are present in the air are important information to support and optimize the allergic disease management.

Besides applications in the field of allergy, aerobiological data can provide other important information, e.g., on the local flora composition, plant phenology, potential crop production and plant conservation (Fernandez-Llamazares et al., 2014), as well as on temporal changes and trends of pollination due to the climate change, when long-time series of airborne pollen data are available (Damialis et al., 2019; Cristofolini et al., 2020; Velasco-Jimenez et al., 2020). Currently, the analysis of samples is routinely based on the visual inspection of morphological features of pollen grains by manual light microscope, which allows their count and identification. This approach is known as very time-consuming and skill-demanding, and since many years the need of automation in palynology is strongly perceived (Stillman and Flenley, 1996). Thus, important efforts have been deployed in the last years in finding alternative automated methods for single-pollen-grain identification. Some of the most exploited and promising approaches are based on the image analysis (Lagerstrom et al., 2015; Oteros et al., 2015, 2020; Sauvageat et al., 2020), spectroscopy techniques (Mondol et al., 2019; Kendel and Zimmermann, 2020) and molecular biology (Leontidou et al., 2018; Rojo et al., 2019).

In addition to the abovementioned active volumetric aerobiological sampling, which is based on the suction principle, airborne samples can be collected also by gravitational settling or by impaction, on a horizontal or vertical surface, respectively. A commercially available passive sampler, which collects particles based on the sedimentation principle, is the Sigma-2 sampler. It has demonstrated its applicability for airborne particulate matter monitoring in various recent studies (Norra et al., 2016; Tian et al., 2017; Sommer et al., 2018). The sampler is designed to collect particles with geometrical equivalent diameters between $2.5 \mu \mathrm{m}$ and $80 \mu \mathrm{m}$ quantitatively (VDI 2119, 2013). Therefore, the Sigma-2 sampler was chosen in this study to collect samples passively, also to test the comparability with the Hirst-type sampler prior to further uses in remote mountainous areas.

On the one hand, active (i) and passive (ii) sampling were compared in this study by conventional light microscopy and manual image analysis, considering the active volumetric (Hirst-type) sampling as the reference method. On the other hand, the automated analyses by optical (iii) and scanning electron (iv) microscopy, implemented on passive samples (Sigma-2), were investigated. Both approaches, (iii) and (iv), were coupled to a fully automated data processing regarding the characterization and classification of individual particles.

In the case of the automated light microscopy method (iii), the idea pursued in this work was firstly to classify particles in dark (mostly of anthropogenic origin) and bright (mostly of natural origin) categories, secondly to distinguish them in size classes, and thirdly to quantify the sedimentation rate and concentration of each size class by means of image analysis. Finally, the focus was set on those particles in the size range(s) corresponding to the mean pollen diameter.

In the case of the automated scanning electron microscopy coupled with energy-dispersive X-ray spectroscopy (SEM/EDX) approach (iv), a set of criteria including morphological (geometric diameter and aspect ratio) and chemical (carbon content) parameters was applied to optimize the analytical time and enable the identification of pollen-like particles. The main objective of this study was to verify the potential of passive sampling combined with fully automated analytical methods in providing reliable data on airborne pollen load. 


\section{METHODS}

\subsection{Study Design and Site Description}

The study was carried out in San Michele all'Adige (Trento, North Italy), at the Adige valley floor (228 $\mathrm{m}$ a.s.I.) (Fig. 1). Here an aerobiological volumetric Hirst-type sampler (VPPS 2000; Lanzoni) has been continuously working since the end of 1980s (https://goo.gl/maps/E8yCiNhhcbGyzcfH8) (Cristofori et al., 2010). In addition, for the purposes of this study, two Sigma-2 passive samplers (Particle Vision, Switzerland) were co-located to the volumetric one. Samples were collected for 12 one-week time intervals in 2018 (Table 1), chosen in order to cover the main local pollen season as much as possible, that occurs from February to mid-November (Cristofori et al., 2010).

Considering a 5-km radius area centered on the aerobiological site, and referring to the CORINE Land Cover classification (CLC 2018 [https://land.copernicus.eu/pan-european/corine-land-cover/ clc2018, last accessed on 14 July 2020]), the largest surface results to be covered by forests and semi-natural vegetation (47.3\%), followed by cultivated areas (44.3\%) and artificial surfaces (8.4\%). Forest areas consist in a mix of conifers (mainly Pinus sylvestris L.), broad-leaved species (with the prevalence of Ostrya carpinifolia Scop.) and transitional woodland-shrubs as Corylus avellana L., Alnus Mill. and Salix L. Cultivated areas are mostly represented by vineyards and apple trees. Artificial surfaces mainly consist of discontinuous urban fabrics since in the surrounding of the aerobiological center some relatively small urban centers are present. In addition, the Adige valley floor is crossed by important communication routes such as the highway A22 (ca. $800 \mathrm{~m}$ away) and the railway, both linking Italy to North Europe through the Brenner pass, besides a local railway and secondary-but sometimes highly busy-roads.

\subsection{Active Volumetric Sampling and Sample Analysis}

Active volumetric sampling was performed using a Hirst-type sampler (VPPS 2000; Lanzoni) installed on the top of a 10-m-high tilting pole. The sampler works by active suction of air with a flow rate of $10 \mathrm{~L} \mathrm{~min}^{-1}$ (i.e., the mean breath rate) provided by a vacuum pump. Each daily sample was manually analyzed by optical microscopy (OM; 400×; Leitz Diaplan). Samples were examined

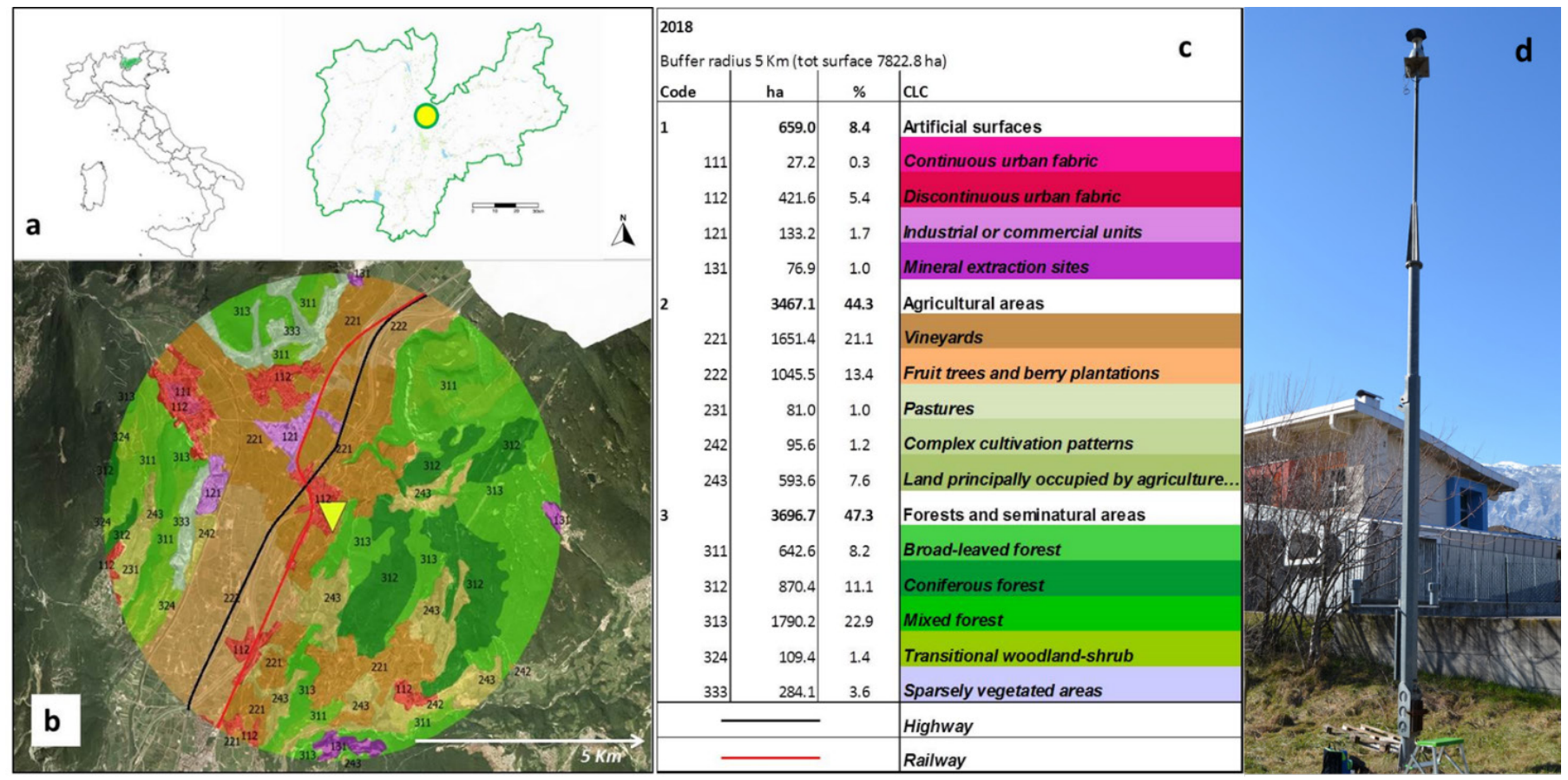

Fig. 1. (a) Study site in San Michele all'Adige, Italy; (b) 5-km radius buffer zone centered on the aerobiological site of San Michele all'Adige showing (c) the different land use categories, listed in table following the CORINE Land Cover classification (CLC 2018). (d) Aerobiological station: the Hirst-type sampler on the top of the pole (at $10 \mathrm{~m}$ above ground) and the two Sigma-2 samplers fasten laterally to the pole at $2 \mathrm{~m}$ above ground level. 
Table 1. Start and end dates and week number of the 12 aerobiological sampling periods in 2018.

\begin{tabular}{llll}
\hline Sampling period & Start date & End date & Week of the year \\
\hline 1 & $29 \mathrm{Jan}$ & $05 \mathrm{Feb}$ & 5 \\
2 & $26 \mathrm{Feb}$ & $05 \mathrm{Mar}$ & 9 \\
3 & $26 \mathrm{Mar}$ & $03 \mathrm{Apr}$ & 13 \\
4 & $16 \mathrm{Apr}$ & $23 \mathrm{Apr}$ & 16 \\
5 & $07 \mathrm{May}$ & $14 \mathrm{May}$ & 19 \\
6 & $28 \mathrm{May}$ & $04 \mathrm{Jun}$ & 22 \\
7 & $18 \mathrm{Jun}$ & $25 \mathrm{Jun}$ & 25 \\
8 & 09 Jul & $16 \mathrm{Jul}$ & 28 \\
9 & $13 \mathrm{Aug}$ & $20 \mathrm{Aug}$ & 33 \\
10 & $10 \mathrm{Sep}$ & $17 \mathrm{Sep}$ & 37 \\
11 & 08 Oct & $15 \mathrm{Oct}$ & 41 \\
12 & 05 Nov & $12 \mathrm{Nov}$ & 45 \\
\hline
\end{tabular}

for pollen identification (Faegri and Iversen, 1989 [https://meteo.fmach.it/polimage, last accessed on 14 July 2020]) and count by a highly trained operator. Daily concentration of pollen per cubic meter of air ( $\mathrm{P} \mathrm{m}^{-3}$; Table 2) was calculated for all identified pollen taxa in the 12 sampling periods (Table 1). Sampling and analysis of airborne pollen were performed following a standard procedure (UNI EN 16868:2019). In order to compare the results with passive sampling, a mean daily concentration was calculated for each one-week sampling period.

\subsection{Passive Sampling and Sample Analysis}

Two gravitational Sigma-2 passive samplers (Particle Vision $\mathrm{GmbH}$, Switzerland) were installed in 2018 at $2 \mathrm{~m}$ above ground level, on the fixed part of the tilting pole where the Hirst-type sampler is positioned. The Sigma-2 passive samplers could not be installed the same height as the Hirst sampler because positioning them on the upper part of the pole would have implied to overturn the sampled surfaces at the times they had to be changed, with the risk to damage them. The Sigma-2 passive sampler was chosen because of its reliability and efficiency (VDI 4330, 2007; VDI 2119, 2013; Waza, 2019) and easy handling; it also allows to adopt different time resolution for sampling.

One sampler was used to expose a $38 \mathrm{~mm} \times 19 \mathrm{~mm}=722 \mathrm{~mm}^{2}$ sampling surface, mounted on a microscope slide, treated and analyzed for pollen grains identification and count by optical microscopy following the same procedure as described in Subsection 2.2. For all identified pollen taxa in each one-week sampling period, the mean daily sedimentation rate $\left(\mathrm{P} \mathrm{cm}^{-2} \mathrm{~d}^{-1}\right.$; Table 2$)$ was calculated dividing the total sedimentation rate value of each taxon by the number of exposure days $(n=7)$ of each sampling slide.

The second sampler was simultaneously used to expose the Sigma-2 adhesive plates, which were analyzed by:

(i) Automated reflected light microscopy by a ZEISS Axio Zoom.V16. For each sampling period, a total surface of $6.5 \mathrm{~mm}^{2}$ (2.3\% of the total sampling surface) was imaged and, to obtain a better image quality and to improve the depth of field, focus stacking with five levels was done. On the resulting images, the image analysis was performed with a macro based on ImageJ software (Abràmoff et al., 2004; Schneider et al., 2012) providing data on geometric parameters and grey values of particles. Mean daily sedimentation rate $\left(\mathrm{P} \mathrm{cm}^{-2} \mathrm{~d}^{-1}\right)$ and concentration in air $\left(\mathrm{P} \mathrm{m}^{-3}\right)$ for different size classes in the range from 2.5 to $80 \mu \mathrm{m}$ (i.e., 2.55, 5-10, 10-20, 20-40, 40-80 $\mu \mathrm{m}$; Table 2) were calculated according to VDI 2119 (2013) assuming a particle density of $1 \mathrm{~g} \mathrm{~cm}^{-3}$. Furthermore, particles were distinguished in bright and dark, based on the grey value obtained from image analysis. This step is of additional value as pollen grains can be assigned always to the bright fraction. Applying two filtering criteria based on size fraction and grey values, those particles that are potentially pollen candidates can be identified.

(ii) Automated scanning electron microscopy coupled to energy-dispersive X-ray spectroscopy was performed by a ZEISS Gemini SEM 300 microscope and an Oxford X-Max $80 \mathrm{~mm}^{2}$ EDX 
detector, followed by a fully automated data processing of the morpho-chemical properties of each analyzed single particle by using the software Particle Classifier (PACLA) (Meier et al., 2018). This analysis, performed on a surface of $19.7 \mathrm{~mm}^{2}$ ( $25.1 \%$ of the total sampling surface), has the potential to enable the automated identification, differentiation and quantification (i.e., sedimentation rate $\left[P \mathrm{~cm}^{-2} \mathrm{~d}^{-1}\right]$, number concentration $\left[\mathrm{P} \mathrm{m}^{-3}\right]$ ) of airborne particles in general, and their allocation to anthropogenic (e.g., road traffic, industrial processes) or natural (e.g., pollen, spores, minerals) sources. In order to optimize the analytical time and achieve the analysis of a larger surface, increasing the statistical relevance, only particles from biogenic sources (i.e., pollen candidates, subsequently named as "pollen-like" particles) were further considered for the analysis (Table 2). This was done by applying a filter during analysis, which helped to preselect the pollen candidates already at the analysis stage. The filter used was a chemical filter, i.e., only particles with a carbon content $>80 \mathrm{wt} . \%$ (normalized excluding oxygen) were chemically analyzed. After chemical analysis, the following morphological characteristics were further considered a prerequisite to classify a particle as "pollen-like": geometric diameter $>10 \mu \mathrm{m}$ and aspect ratio $<2.2$ (i.e., major/minor particle diameter ratio). These parameters were selected because they are in concordance with the observations made by the manual OM (reference method).

Additionally, a set of pollen reference (Supplemental Table), purposely collected from fully flowering plants, was previously analyzed by automated SEM/EDX aiming to determine their specific morpho-chemical fingerprint. Even though some of these samples showed a large overlapping in their morpho-chemical characteristics (e.g., same elemental composition with very similar sizes and morphologies), which makes a differentiation of pollen taxa extremely difficult, common features could be used to better differentiate the pollen grains from other particles, in general (e.g., content of trace elements like $\mathrm{Ca}, \mathrm{Mg}, \mathrm{K}, \mathrm{S}, \mathrm{P}$ ) (see Fig. 2 as an example).

\subsection{Data Analysis}

To compare the two lists of pollen taxa obtained by active (A) and passive (B) sampling in the twelve sampling periods, the Jaccard index $\left(\mathrm{J}_{\mathrm{i}}\right)$ was calculated as the ratio between the number of taxa in the intersecting set divided by the number of taxa in the union of 


\section{Ostrya carpinifolia pollen}

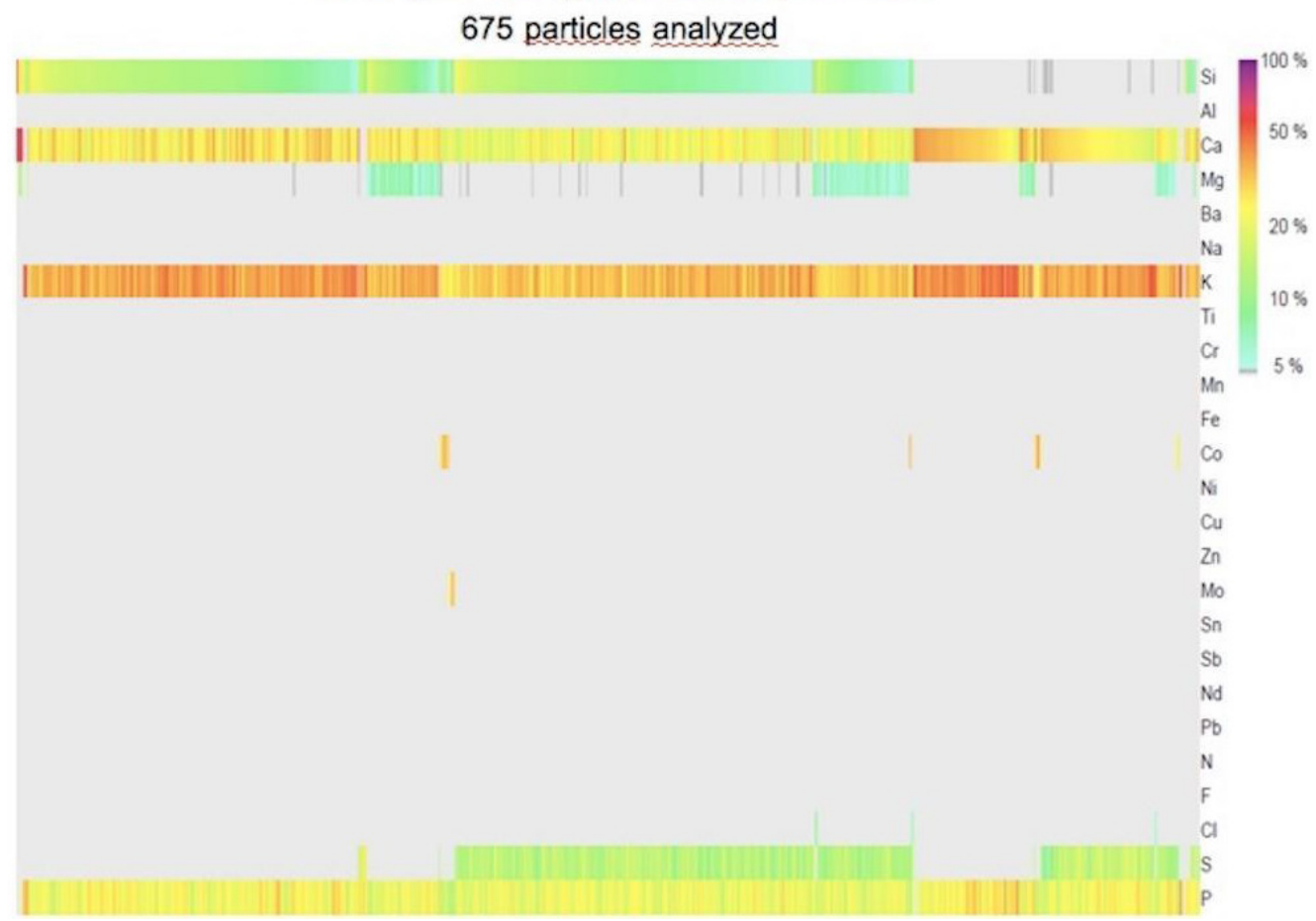

Fig. 2. Elemental composition of Ostrya carpinifolia (European hop-hornbeam) pollen (carbon (C) and oxygen (O) excluded) analyzed by SEM/EDX.

the two data sets. It represents a measure of similarity between two sets of data, with values ranging from 0 (no pollen taxa shared) to 1 (all pollen taxa shared).

The Spearman rank-order correlations was applied between data sets of pollen, obtained by manual OM and automated SEM/EDX, and pollen-candidate particles obtained by automated $\mathrm{OM}$; both sedimentation rates and concentration values were considered. For this comparison, the software Statistica (version 13 [http://statistica.io/]; TIBCO Software Inc., 2017) was used.

\section{RESULTS}

\subsection{Manual Optical Microscopy Analysis}

\subsubsection{Active sampling (reference method)}

The pollen analysis carried out manually by OM on samples obtained by active volumetric sampling allowed to identify 56 pollen taxa (Supplemental Table). The 12 most abundant taxa covered the $90.1 \%$ of the total pollen sampled (Fig. 3(a)). The only Ostrya carpinifolia (European hop-hornbeam) represented more than half (51.6\%) of the pollen spectrum, followed by the family Urticaceae (13.0\%)-mostly represented in these samples by the genus Parietaria (pellitory) - and by Fraxinus ornus (manna ash; 4.6\%).

The mean size of collected pollen types was $34.1 \pm 23.09 \mu \mathrm{m}$ (min: $13.1 \mu \mathrm{m}$; max: $124.8 \mu \mathrm{m})$. Fig. 3(b) shows the daily mean of pollen concentrations collected in the 12 sampling periods, distinct in six size classes. As expected, no pollen grains were found in the $2.5-5 \mu \mathrm{m}$ and $5-10 \mu \mathrm{m}$ classes. The smallest pollen grains lay in the $10-20 \mu \mathrm{m}$ range, which covered the $16.3 \%$ of total pollen and was mostly represented by the family Urticaceae ( $80.8 \%$ of the size class). The largest amount $(79.3 \%)$ of all sampled pollen grains resulted to be allocated in the $20-40 \mu \mathrm{m}$ range, where Ostrya carpinifolia covered the $65.4 \%$ of the size class. The $40-80 \mu \mathrm{m}$ size class (3.9\% of total pollen) was largely covered by the genus Pinus ( $81.8 \%$ of the size class). Very few of sampled grains $(0.6 \%$ of the total pollen) were larger than $80 \mu \mathrm{m}$, mostly belonging to the genus Picea $(96.7 \%$ of the size class). Fig. 4 shows the most abundant pollen taxon for each pollen grain size class. 


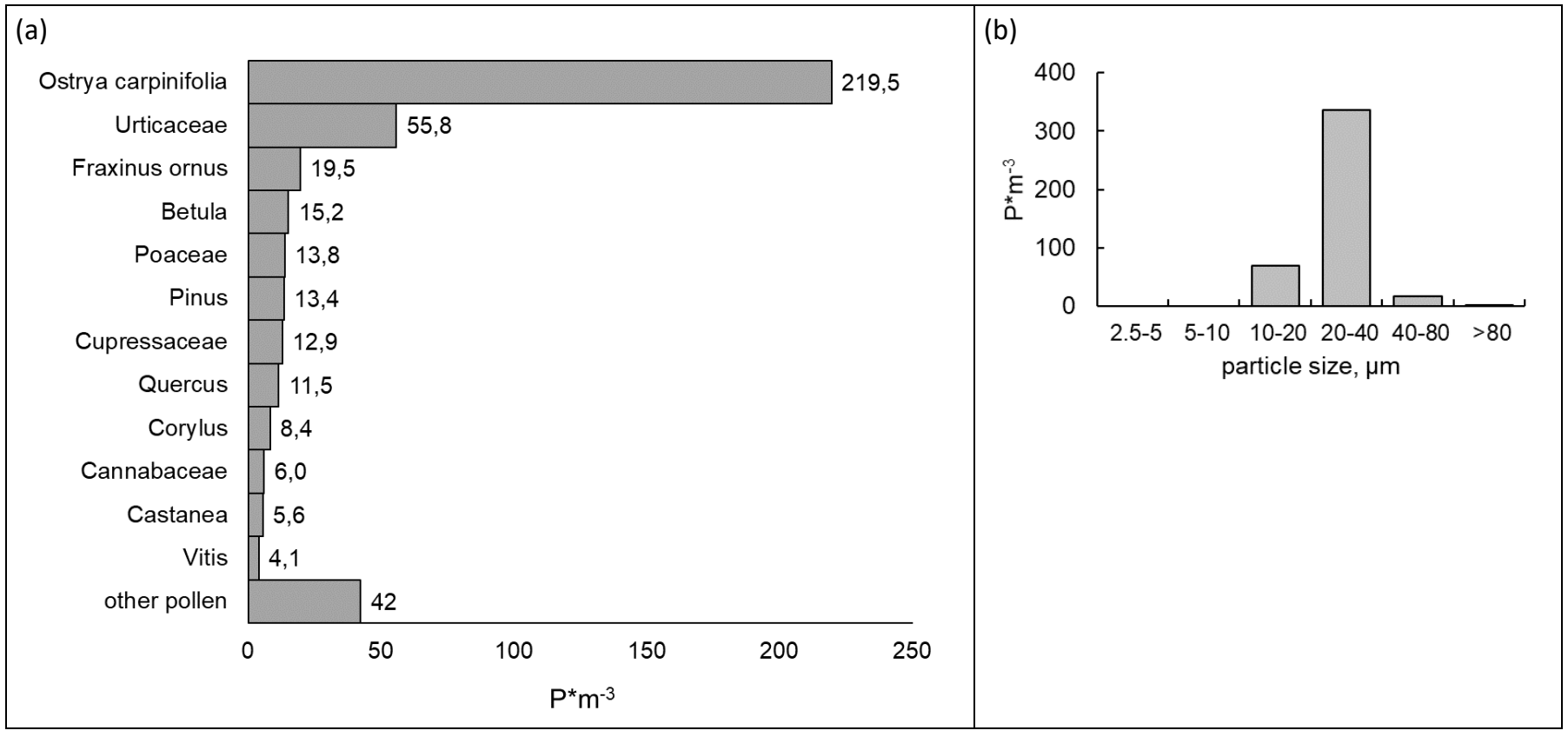

Fig. 3. Mean daily concentration in air $\left(\mathrm{P} \mathrm{m}^{-3}\right)$ of the first 12 most abundant airborne pollen taxa obtained by the active sampling during the 12 sampling periods: (a) analyzed by manual optical microscopy and (b) values for pollen size classes.

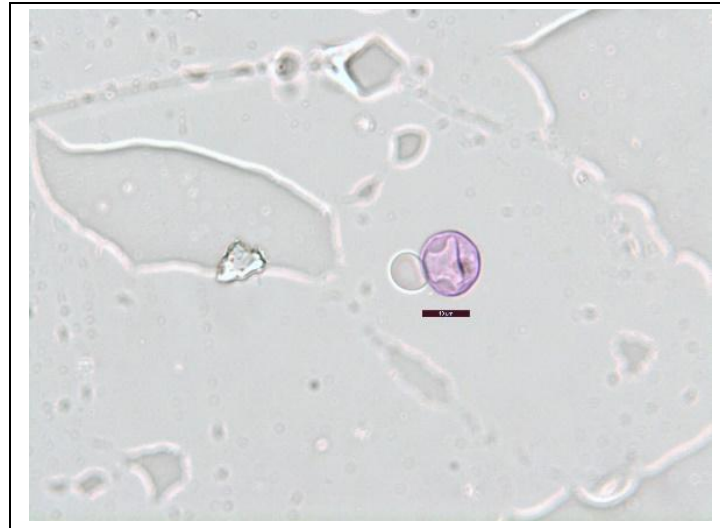

(a) 10-20 $\mu \mathrm{m}$ : Parietaria sp.

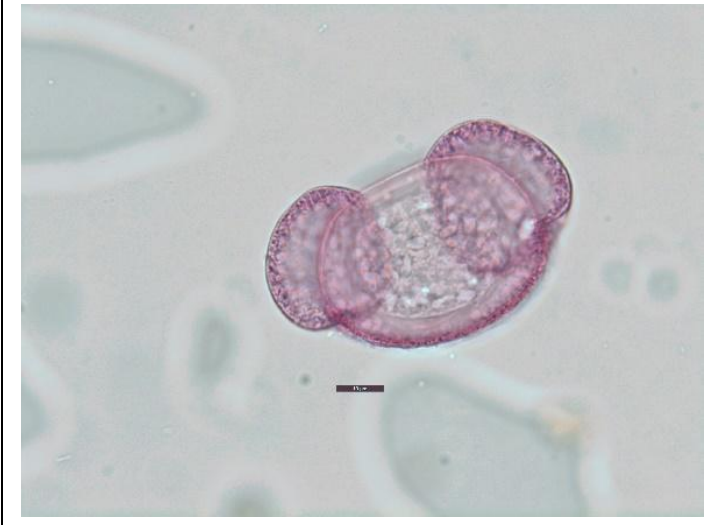

(c) 40-80 $\mu \mathrm{m}$ : Pinus sp.

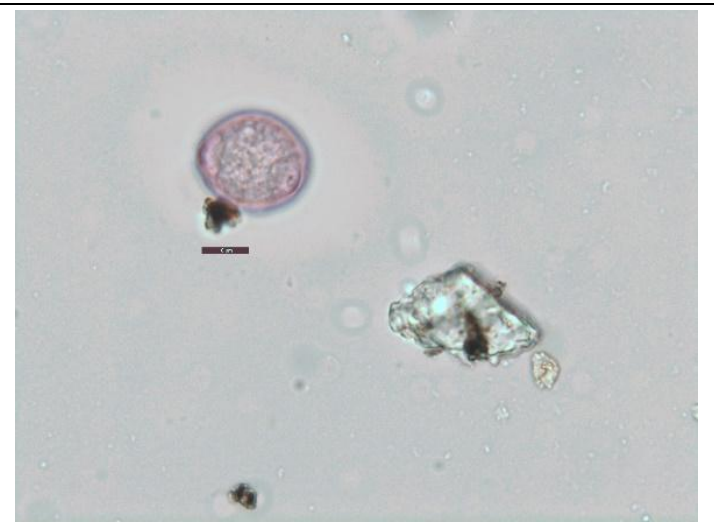

(b) 20-40 $\mu \mathrm{m}$ : Ostrya carpinifolia

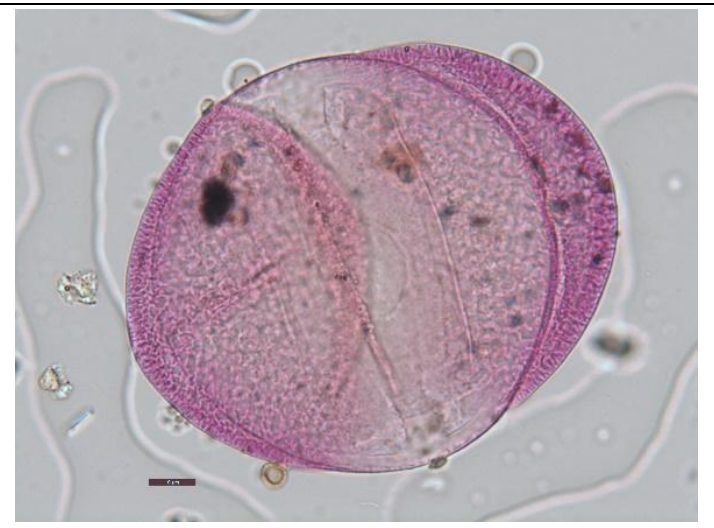

(d) $>80 \mu \mathrm{m}$ : Picea sp.

Fig. 4. The most representative pollen taxon for each size class, both in active and passive samples: (a) 10-20 $\mu \mathrm{m}$, Parietaria sp. (Urticaceae) (from passive sample, Period 9); (b) 20-40 $\mu \mathrm{m}$, Ostrya carpinifolia (from passive sample, Period 4); (c) 40-80 $\mu \mathrm{m}$, Pinus sp. (from passive sample, period 5); (d) $>80 \mu \mathrm{m}$, Picea sp. (from passive sample, Period 5). The black scale bar close to each pollen grain corresponds to $10 \mu \mathrm{m}$. Pictures were taken on passive sampling slides (ocular 10×, objective 60/0.90; UPlanApo on Microscope Model BX51; Olympus). 


\subsubsection{Passive sampling and comparison with data from active sampling}

Overall, 55 pollen taxa were identified on samples obtained by passive sampling and analyzed by manual OM (Supplemental Table 1). The first 12 most frequent taxa covered $87.5 \%$ of the total pollen sampled (Fig. 5(a)). As with active sampling, on passive samples Ostrya carpinifolia was the most abundant (47.7\%), followed by the Poaceae (7.5\%) and Urticaceae (6.1\%) families. Fig. 5(b) shows the mean daily pollen sedimentation rates in the 12 sampling periods per size class. As observed for concentration values, the most abundant pollen grains were in the $20-40 \mu \mathrm{m}$ size class, followed by the 10-20 $\mu \mathrm{m}$ one. Again, Urticaceae pollen was the most representative in the $10-20 \mu \mathrm{m}$ class $(64.2 \%)$, Ostrya carpinifolia in the $20-40 \mu \mathrm{m}$ class $(59.7 \%)$, Pinus in the $40-$ $80 \mu \mathrm{m}$ class ( $81.4 \%$ ) and Picea in the $>80 \mu \mathrm{m}$ class (90.1\%) (Fig. 4).

Comparing the data from active and passive sampling (Fig. 6(a)), the frequency of the smallest pollen grains $(10-20 \mu \mathrm{m})$ resulted higher for the active sampling than for the passive one. On the contrary, a higher fraction of pollen larger than $40 \mu \mathrm{m}$ was detected on passive samples in comparison to the active ones.

Comparing the two pollen spectra obtained by passive and active sampling, i.e., the frequency of each pollen taxon collected during the 12 sampling periods (Supplemental Table), a highly significant correlation $(p<0.001)$ resulted between pollen sedimentation rates (i.e., by passive sampling) and concentrations in the air (i.e., by active sampling) (Fig. 6(b)).

Table 3 reports the number of pollen taxa identified on active and passive samples in the 12 sampling periods and over the entire study period, and the related Jaccard similarity index. Overall, the similarity between the two lists of taxa resulted high with $72 \%$ of taxa in common between the two sampling methods (i.e., $\mathrm{J}_{\mathrm{i}}=0.72$ ). The taxa not in common were rare, consisting in only $0.16 \%$ of total pollen grains collected by passive sampling, and $0.05 \%$ of total pollen grains collected by active sampling.

\subsection{Automated Image Analysis of Passive Samples}

\subsubsection{Automated optical microscopy}

Fig. 7 shows the mean daily sedimentation rates $\left(\mathrm{P} \mathrm{cm}^{-2} \mathrm{~d}^{-1}\right)$ of bright and dark particles in the five size classes for the 12 sampling periods. The sedimentation rate values of both types of particles decreased with increasing particle size within each period. The exception was in Period 4 where the 20-40 $\mu \mathrm{m}$ fraction of bright particles was larger than the 10-20 $\mu \mathrm{m}$ fraction in the same period, and also than the same size class in all the other sampling periods.

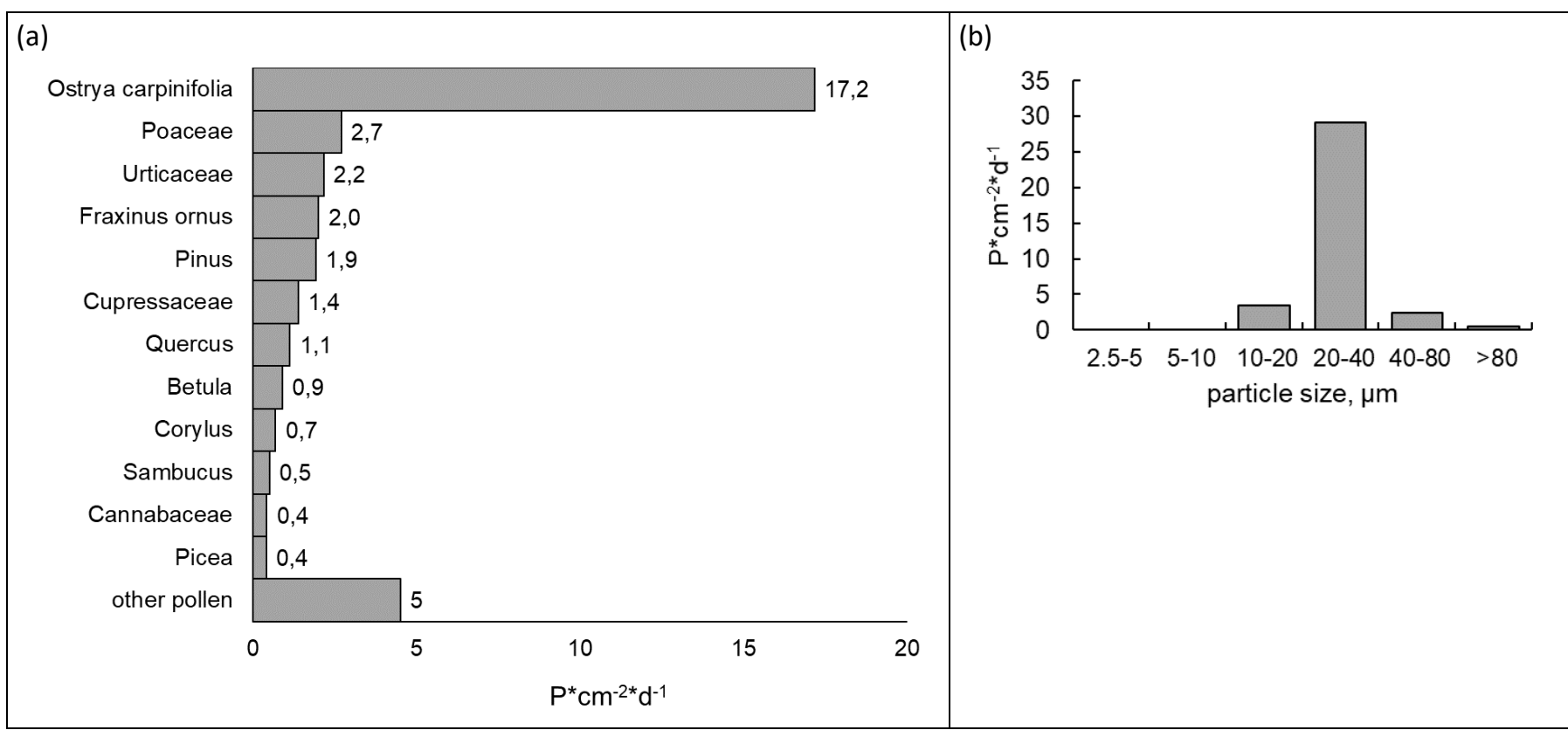

Fig. 5. Mean daily sedimentation rate $\left(\mathrm{P} \mathrm{cm}^{-2} \mathrm{~d}^{-1}\right)$ of the first 12 most abundant airborne pollen taxa obtained by passive sampling during the 12 sampling periods: (a) analyzed by manual optical microscopy and (b) sorted in pollen size classes. 


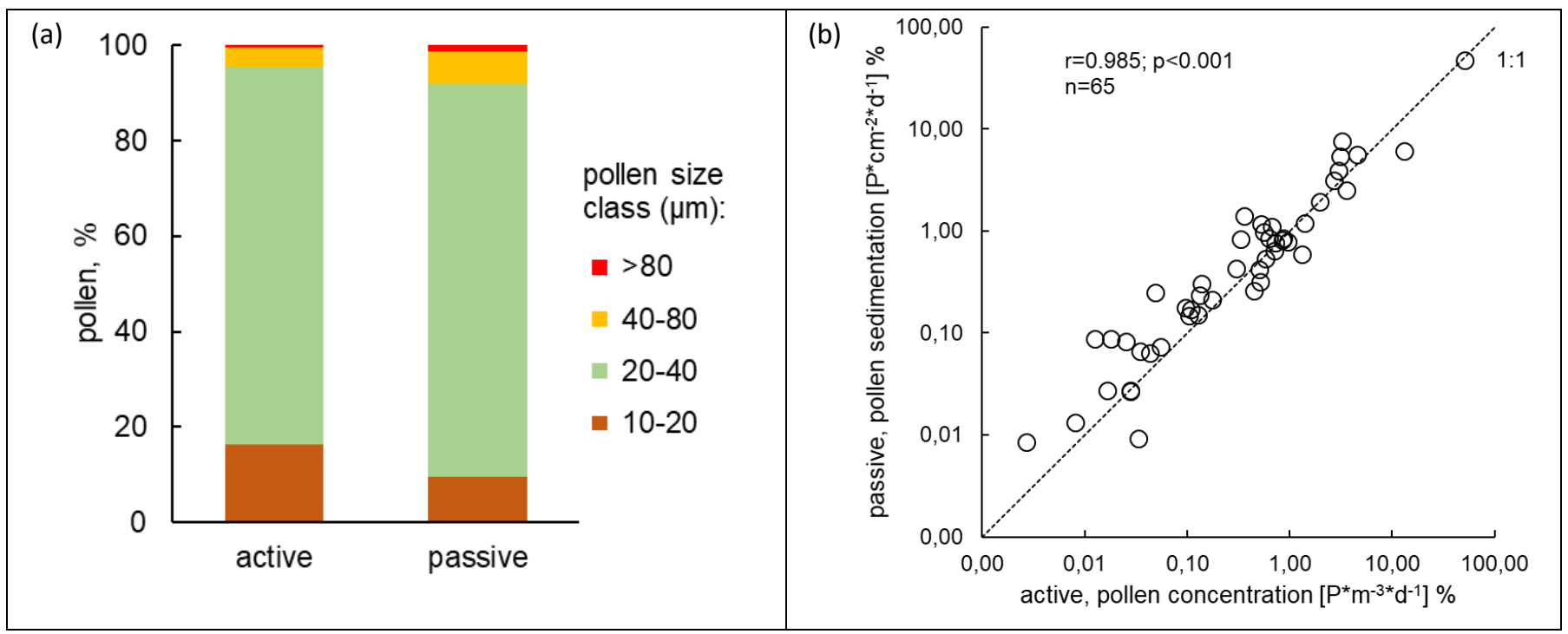

Fig. 6. Comparison between active (Hirst-type) and passive (gravitational slides) sampling, both manually analyzed by light microscopy, in terms of (a) frequency of pollen per grain size class, and (b) frequency of pollen for each taxon detected, in logarithmic scale (data reported in the Supplemental Table); correlation values ( $r$ and $p$ ) are reported.

Table 3. Number of pollen taxa identified on active and passive samples in the 12 sampling periods and over the entire study period, and related Jaccard similarity index.

\begin{tabular}{|c|c|c|c|c|c|c|c|c|c|c|c|c|c|}
\hline \multirow{2}{*}{ Sampling method } & \multicolumn{12}{|c|}{ Sampling period } & \multirow{2}{*}{ TOT } \\
\hline & 1 & 2 & 3 & 4 & 5 & 6 & 7 & 8 & 9 & 10 & 11 & 12 & \\
\hline Active, pollen taxa $n$. & 4 & 8 & 20 & 37 & 30 & 19 & 25 & 19 & 13 & 13 & 11 & 5 & 56 \\
\hline Passive, pollen taxa $n$. & 4 & 12 & 18 & 31 & 27 & 23 & 21 & 16 & 18 & 14 & 10 & 5 & 55 \\
\hline Jaccard index & 0.60 & 0.33 & 0.81 & 0.74 & 0.73 & 0.62 & 0.64 & 0.52 & 0.41 & 0.69 & 0.62 & 0.43 & 0.72 \\
\hline
\end{tabular}

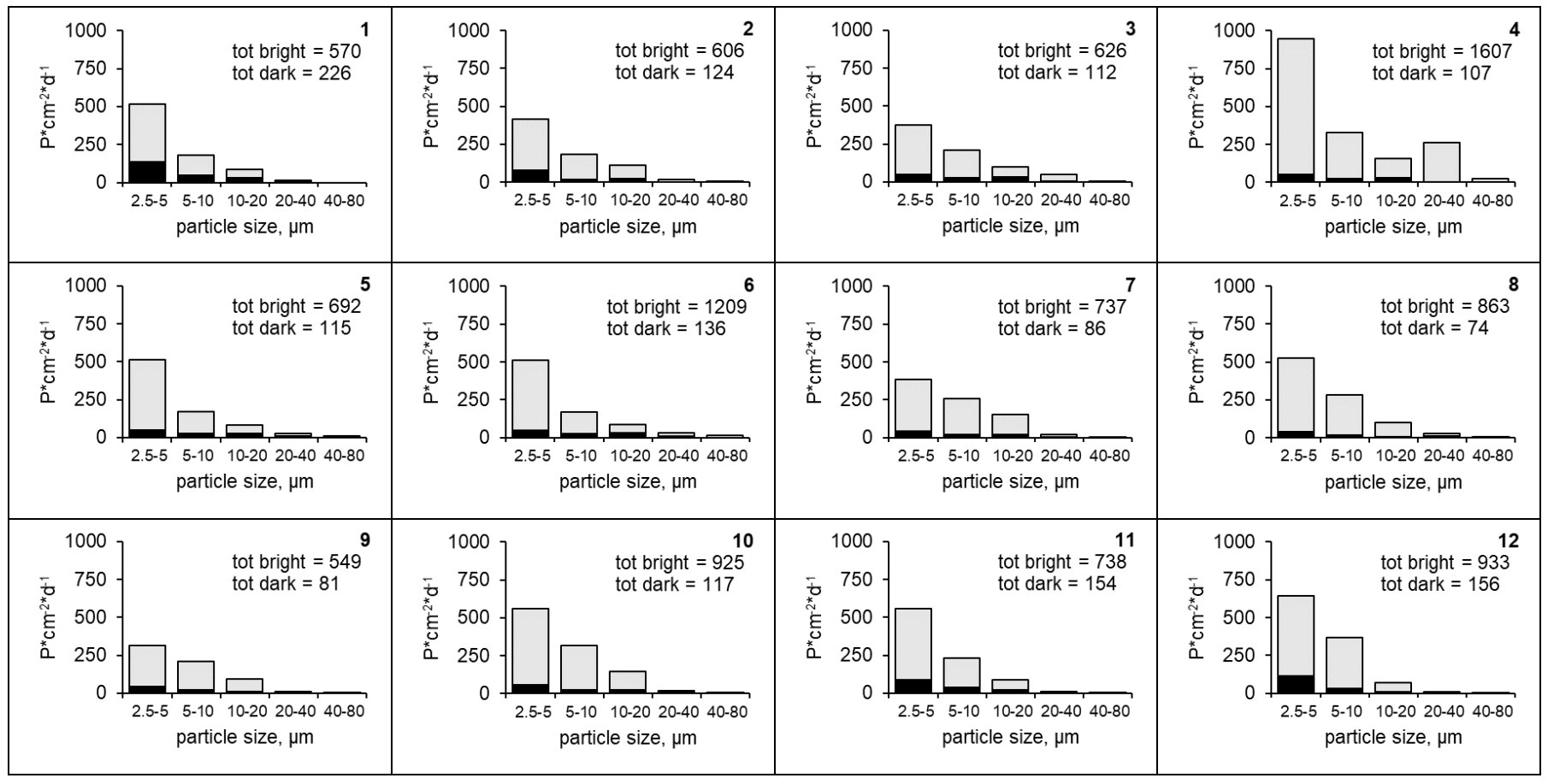

Fig. 7. Number of bright (grey) and dark (black) particles per square centimeter and day $\left(\mathrm{P} \mathrm{cm}^{-2} \mathrm{~d}^{-1}\right)$, collected by sedimentation on Sigma-2 plates in each of the 12 one-week sampling periods in 2018 and analyzed by automated optical microscopy, separated in the five size classes. Total numbers of bright and dark particles for each period are reported. 
Dark anthropogenic particles represented $13 \%$ of the total $2.5-80 \mu \mathrm{m}$ particles collected during the 12 one-week sampling periods, and showed a seasonal pattern with the lowest values in spring and summer and the highest values in autumn and winter. Dark particle fraction is generally composed by soot derived from combustion (exhaust vehicle emissions and heating systems) and by particles from abrasive processes as wear of car brakes and tires. Giving their inorganic origin, the dark fraction of particles was not further considered because it does not comprise pollen grains, i.e., the target of this study.

\subsubsection{SEM/EDX and PACLA}

Automated SEM/EDX analysis and data processing of the morpho-chemical properties of each analyzed single particle using the software PACLA, resulted in 652 particles classified as "pollenlike" for all 12 sampling periods. The size-dependent sedimentation rate of pollen-like particles determined by automated SEM/EDX (Fig. 8(a)) shows in the broad sense a similar pattern to that of pollen manually identified by OM on passive samples (Fig. 5(b)), with the $20-40 \mu \mathrm{m}$ size range as the most abundant class. Follows the 10-20 $\mu \mathrm{m}$ size class that represents a higher fraction (36.4\%) of total pollen-like particles in comparison to the correspondent pollen size fraction (9.6\%). The mean size of collected pollen-like particles was $22.8 \pm 8.53 \mu \mathrm{m}$ ( $\min : 9.9 \mu \mathrm{m}$; max: $82.9 \mu \mathrm{m})$. The pollen-like particle concentrations show the highest value in the $10-20 \mu \mathrm{m}$ size range, closely followed by the 20-40 $\mu \mathrm{m}$ one (Fig. 8(b)). The elemental composition of the pollen-like particles showed that carbon (C) and oxygen (O) represent in total more than $90 \%$ of the pollen weight (wt.\%). The other most frequently detected elements (i.e., present in at least $10 \%$ of analyzed pollen-like particles), normalized without $\mathrm{C}$ and $\mathrm{O}$, are reported in Fig. 9. In decreasing order, they resulted to be: $\mathrm{K}, \mathrm{Ca}, \mathrm{P}, \mathrm{N}, \mathrm{S}, \mathrm{Si}, \mathrm{Mg}$ and $\mathrm{Cl}$.

\subsection{Comparison of Methods}

\subsubsection{Pollen identified by manual optical microscopy vs. bright particles identified by automated optical microscopy}

Table 4 reports the correlations between pollen manually identified by OM and bright particles automatically analyzed by OM, both for the sedimentation rates and concentrations in air. The comparisons were carried out between the total pollen and the bright particles sorted in different size classes, and between the same size classes both for pollen and bright particles. The purpose was to detect the size fraction of bright particles that better represents the total pollen load. Results showed a highly significantly positive correlation $(p<0.001)$ between sedimentation of total pollen and the $20-80 \mu \mathrm{m}$ size range of particles, which is identified as the pollen-candidate fraction. The comparisons between pollen and particles of the same size range showed a positive significant correlation also for the $20-40 \mu \mathrm{m}$ and $40-80 \mu \mathrm{m}$ fractions and the $20-80 \mu \mathrm{m}$ fraction $(p<0.01)$, both for sedimentation and concentration values. No significant correlations were found when the smallest particles were considered, i.e., the 10-20 $\mu \mathrm{m}$ fraction alone or grouped with the $20-40 \mu \mathrm{m}$ one (i.e., $10-40 \mu \mathrm{m}$ ).

(a)

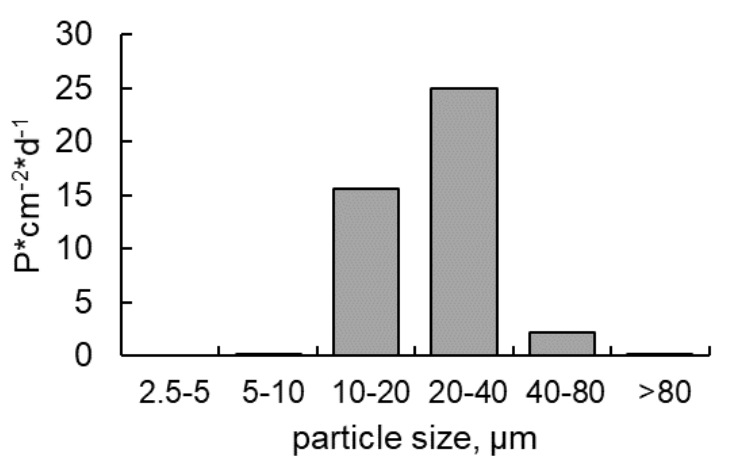

(b)

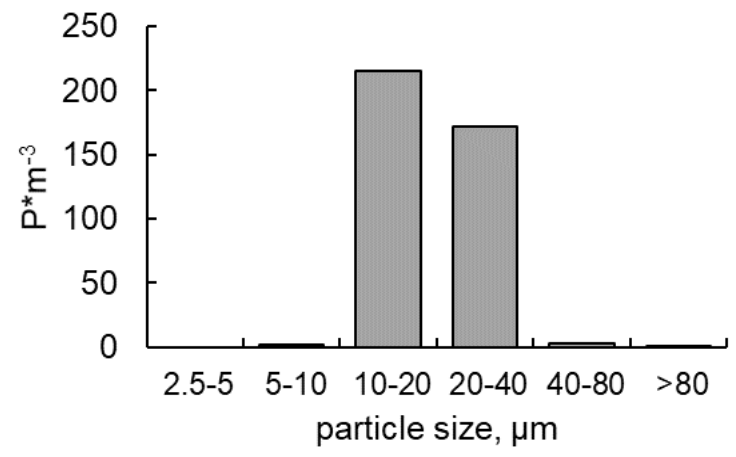

Fig. 8. (a) Mean daily sedimentation rate and (b) particle concentration in air of the pollen-like particles obtained by passive sampling during the 12 sampling periods, analyzed by automated SEM/EDX, sorted in size classes. 


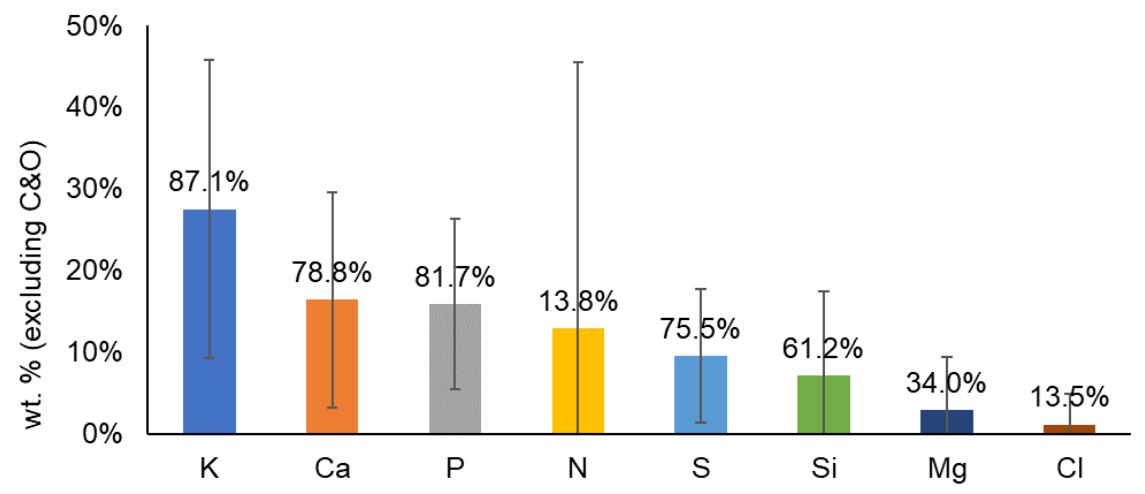

Fig. 9. Elemental composition (carbon (C) and oxygen (O) excluded) of pollen-like particles collected by Sigma-2 passive sampling and analyzed by SEM/EDX. The occurrence frequency of each element in the data set of the analyzed pollen-like particles $(n=652)$ is also reported on top of each column; error bars represent the standard deviation.

Table 4. Spearman rank-order correlation ( $r_{s}$ and $p$ values) between pollen determined by manual optical microscopy (OM; passive sampling for sedimentation rates and active sampling for concentrations) and bright particles determined by automated OM. Results are separated after size classes and both for sedimentation rates and particle number concentrations in air. Nonsignificant (n.s.) correlations are also reported.

\begin{tabular}{|c|c|c|c|c|c|c|}
\hline \multirow{2}{*}{ Pollen by manual OM } & \multirow{2}{*}{ vs. } & \multirow{2}{*}{$\begin{array}{l}\text { Bright particles by } \\
\text { automated OM }\end{array}$} & \multicolumn{2}{|c|}{ Sedimentation rate } & \multicolumn{2}{|c|}{ Concentration in air } \\
\hline & & & $r_{s}$ & $p$ & $r_{s}$ & $p$ \\
\hline Total & & $10-20 \mu \mathrm{m}$ & 0.294 & n.s. & 0.217 & n.s. \\
\hline Total & & $20-40 \mu \mathrm{m}$ & 0.792 & $p<0.01$ & 0.601 & $p<0.05$ \\
\hline Total & & $40-80 \mu \mathrm{m}$ & 0.707 & $p<0.05$ & 0.657 & $p<0.05$ \\
\hline Total & & $10-40 \mu \mathrm{m}$ & 0.517 & n.s. & 0.301 & n.s. \\
\hline Total & & $20-80 \mu \mathrm{m}$ & 0.834 & $p<0.001$ & 0.669 & $p<0.05$ \\
\hline Total & & $10-80 \mu \mathrm{m}$ & 0.580 & $p<0.05$ & 0.301 & n.s. \\
\hline 10-20 $\mu \mathrm{m}$ & & $10-20 \mu \mathrm{m}$ & 0.424 & n.s. & 0.578 & $p<0.05$ \\
\hline 20-40 $\mu \mathrm{m}$ & & $20-40 \mu \mathrm{m}$ & 0.617 & $p<0.05$ & 0.629 & $p<0.05$ \\
\hline $40-80 \mu \mathrm{m}$ & & $40-80 \mu \mathrm{m}$ & 0.758 & $p<0.01$ & 0.615 & $p<0.05$ \\
\hline 10-40 $\mu \mathrm{m}$ & & 10-40 $\mu \mathrm{m}$ & 0.483 & n.s. & 0.420 & n.s. \\
\hline $20-80 \mu \mathrm{m}$ & & $20-80 \mu \mathrm{m}$ & 0.736 & $p<0.01$ & 0.694 & $p<0.05$ \\
\hline
\end{tabular}

\subsubsection{Pollen identified by manual optical microscopy vs. pollen-like particles identified by automated SEM/EDX}

Table 5 reports the correlations between pollen manually identified by OM and pollen-like particles obtained by the automated SEM/EDX followed by the morpho-chemical analysis, both for the sedimentation and concentration values. The correlation between the total pollen and the total pollen-like particles resulted highly significant, both for the sedimentation and concentration in air $(p<0.001)$. Significant correlations were observed also between the different size ranges, except for the fraction $40-80 \mu \mathrm{m}$ for concentrations and for the fraction $>80 \mu \mathrm{m}$ for sedimentation and concentration, probably because of the small number of particles in these size ranges (Figs. 5(b) and $8(a)$ ). Note that a higher relative measurement uncertainty is giving for the larger particle fraction due to low counts per analyzed surfaces.

\subsubsection{Time pattern of pollen, pollen-like and pollen-candidate particles sedimentation}

Fig. 10 shows the highly significant positive correlation detected between the mean daily sedimentation rates of pollen (from manual $\mathrm{OM}$ ) and (a) the pollen-candidate particles (from automated OM, defined as the $20-80 \mu \mathrm{m}$ bright particles fraction), and (b) the pollen-like particles (from automated SEM/EDX and morpho-chemical filters). The time pattern of mean daily 
Table 5. Spearman rank-order correlation ( $r_{s}$ and $p$ values) between pollen determined by manual optical microscopy (OM; passive sampling for sedimentation rates and active sampling for concentrations) and pollen-like particles determined by automated SEM/EDX. Results are separated after size classes and, both for sedimentation rates and particle number concentrations in air. Non-significant (n.s.) correlations are also reported.

\begin{tabular}{|c|c|c|c|c|c|c|}
\hline \multirow{2}{*}{ Pollen by manual OM } & \multirow{2}{*}{ vs. } & \multirow{2}{*}{$\begin{array}{l}\text { Pollen-like particles by } \\
\text { automated SEM/EDX }\end{array}$} & \multicolumn{2}{|c|}{ Sedimentation rate } & \multicolumn{2}{|c|}{ Concentration in air } \\
\hline & & & $r_{s}$ & $p$ & $r_{s}$ & $p$ \\
\hline Total & & Total & 0.825 & $p<0.001$ & 0.923 & $p<0.001$ \\
\hline $10-20 \mu \mathrm{m}$ & & $10-20 \mu \mathrm{m}$ & 0.865 & $p<0.001$ & 0.698 & $p<0.05$ \\
\hline $20-40 \mu \mathrm{m}$ & & 20-40 $\mu \mathrm{m}$ & 0.818 & $p<0.01$ & 0.832 & $p<0.001$ \\
\hline $40-80 \mu \mathrm{m}$ & & $40-80 \mu \mathrm{m}$ & 0.624 & $p<0.05$ & 0.508 & n.s. \\
\hline$>80 \mu \mathrm{m}$ & & $>80 \mu \mathrm{m}$ & 0.513 & n.s. & 0.536 & n.s. \\
\hline
\end{tabular}
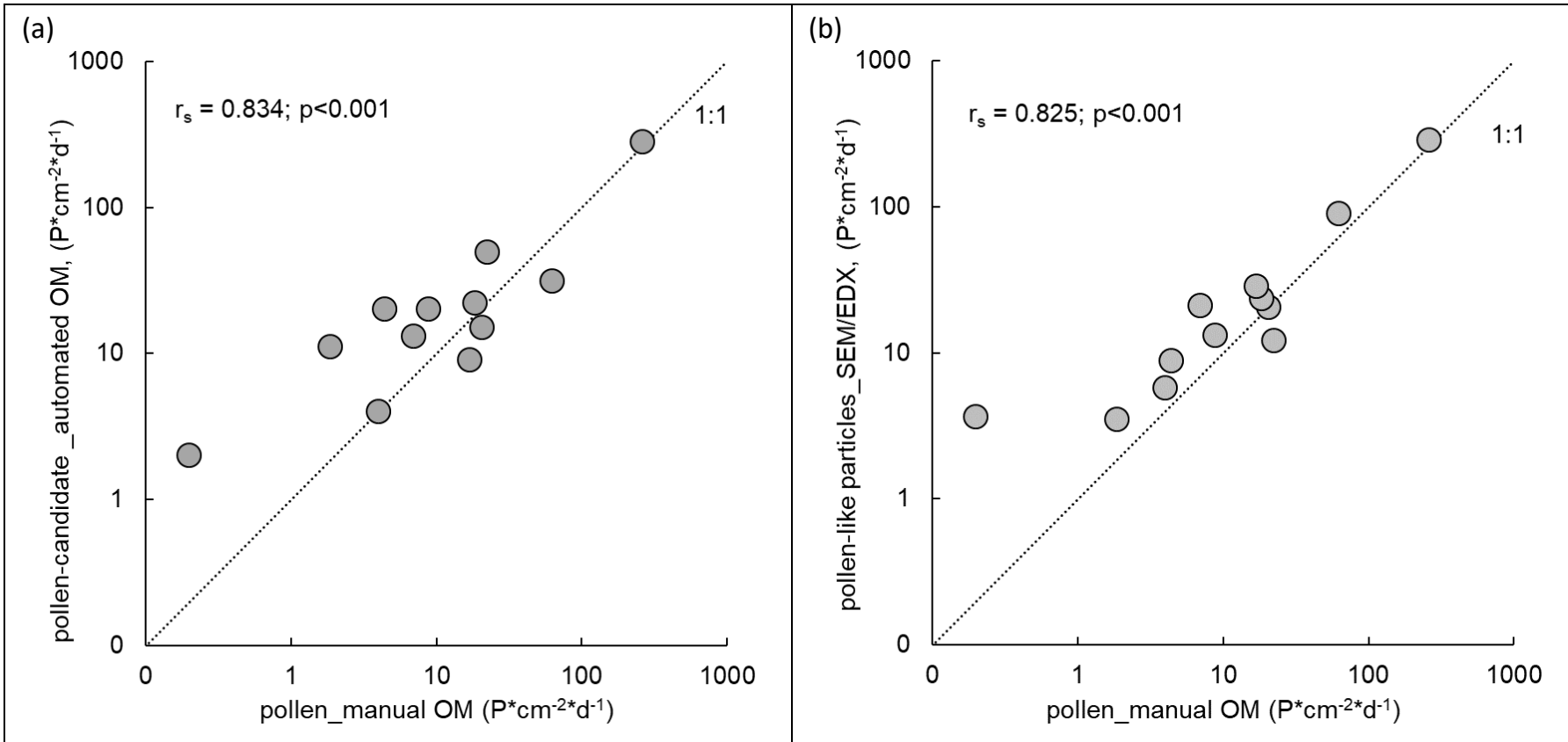

(c)

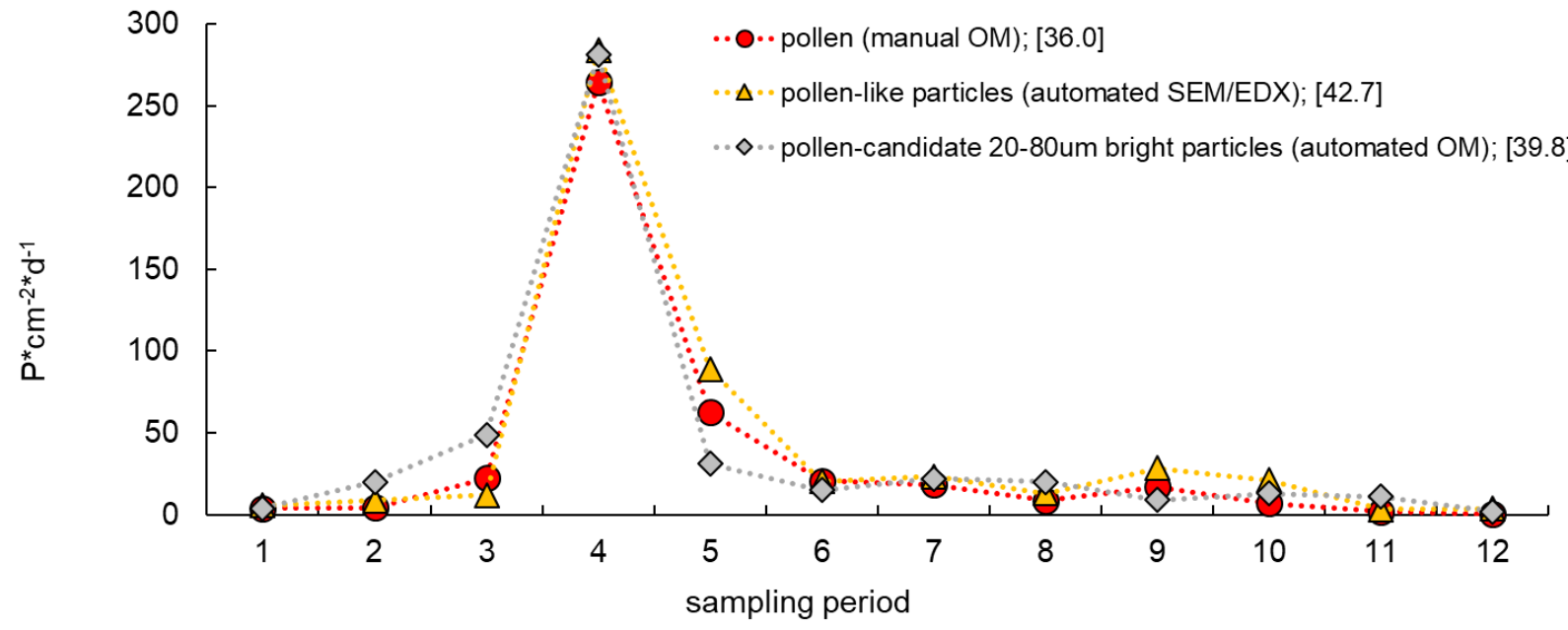

Fig. 10. Correlations between mean daily sedimentation rates of pollen collected on slides and analyzed by manual optical microscopy and (a) pollen-candidate $20-80 \mu \mathrm{m}$ bright particles, collected on Sigma-2 plates and analyzed by automated optical microscopy and (b) pollen-like particles collected on Sigma-2 plates and analyzed by automated SEM/EDX and morpho-chemical classification. (c) Mean daily sedimentation rates for the 12 sampling periods of pollen (red circles), pollen-like particles (yellow triangles), and pollen-candidate particles (grey quadrates). Mean sedimentation values over the entire study period of the three particle categories are reported in the legend, in square brackets. 
sedimentation rates of pollen, pollen-candidate and pollen-like particles along the 12 sampling periods is shown in Fig. 10(c). Pollen sedimentation rates represent well the seasonality of pollen along the year, with the highest values in spring and summer (max: $264.4 \mathrm{P} \mathrm{cm}^{-2} \mathrm{~d}^{-1}$, Period 4), when most of plants flower, and the lowest values in autumn and winter (min: $0.2 \mathrm{P} \mathrm{cm}^{-2} \mathrm{~d}^{-1}$, Period 12), when the biogenic plant activity is the lowest. The coherence between the time pattern of pollen, pollen-candidate and pollen-like particles is evident. These three data series display the same peak in Period 4, when Ostrya carpinifolia resulted to be the most abundant pollen in the samples (76\%).

\section{DISCUSSION}

With this work we concurrently verified: (i) the reliability of airborne pollen sampling by means of Sigma-2 passive sampler in comparison to the volumetric Hirst-type sampler, analyzing both types of samples for the identification and quantification of pollen grains on the basis of their morphological features by OM; (ii) the possibility to distinguish the total pollen fraction within the particles collected by the passive Sigma-2 sampler applying automated analytical approaches based on optical and scanning electron microscopy.

(i) Firstly, the passive sampling resulted to work well in comparison to the active one, both in terms of total number of pollen taxa collected and related frequencies. This is an important result per se since Sigma-2 passive sampling proved to be able to easily provide reliable aerobiological samples that can be further analyzed with different approaches. Even if the Hirst-type sampler has advantages in terms of data temporal resolution (from hourly to daily data), passive sampling is based on simpler and cheaper instruments, and allows studies in unattended remote setups (no power supply needed). Slight differences between the two sampling methods were observed for pollen size class distribution, with a larger fraction of the smaller pollen (i.e., 10-20 $\mu \mathrm{m}$ ) in the active samples and of the bigger pollen (i.e., $>40 \mu \mathrm{m}$ ) in passive samples. Considering that the Sigma-2 sampler results to be less efficient than the Hirst-type in collecting bigger pollen grains (Miki et al., 2019), the observed differences are probably attributable to the different installation height of the two types of samplers (Alcazar, 1999): The better flight capacity of smaller pollen grains due to their lower sedimentation velocities makes them suitable to reach higher heights, where the volumetric Hirst-type sampler was installed (i.e., $10 \mathrm{~m}$ above the ground), while bigger pollen grains are more affected by the gravitational force and therefore are more prone to fly in the lower air layers, where the Sigma-2 passive samplers were installed (i.e., $2 \mathrm{~m}$ above the ground). However, the most abundant pollen taxa (72\%) were common in the two sample types, while the exclusive taxa accounted only for $0.1 \%$ and $0.2 \%$ of the pollen grains collected respectively by active and passive sampling.

(ii) As for the automated analytical methods, we successfully verified that particle size and grey values were appropriate filtering criteria to detect the pollen candidates by automated OM: Bright (mainly of natural origin) particles in the $20-40 \mu \mathrm{m}$ and $40-80 \mu \mathrm{m}$ size ranges resulted to be well correlated with the correspondent fractions of pollen microscopically identified and quantified by trained operators. However, the interference with other bright particles in the size fraction 10-20 $\mu \mathrm{m}$, spores included, may be the reason for the impaired correlation. Similarly, filtering the particles based on size, shape and chemical criteria, the automated SEM/EDX technique allowed to select the pollen-like fraction. When total values were considered, both sedimentation rates and concentration values of pollen-like particles were highly correlated with manually analyzed pollen. Pollen-like size distribution obtained by SEM/EDX resulted in an offset towards smaller size classes compared to the other methods, and this is probably due to the shrinkage to which biological particles are subjected in low pressure in the SEM chamber as well as under the electron beam (Halbritter, 1998). This physical effect could also explain the lack of correlation with pollen obtained by manual OM, when concentration values are referred to the $40-80 \mu \mathrm{m}$ size range; this size range is mostly represented by the pollen of Pinus, whose air sacs are likely more prone to collapse under the SEM conditions. Since the calculation of concentration from sedimentation values depends also on the geometric diameter of particles, this may have led to an overestimation of lower particle concentration. 
The individual particle characterization based on scanning electron microscopy coupled with energy-dispersive analysis has been already implemented (Rivera and Rodriguez, 2016), allowing to distinguish, among others, the fraction of biological carbonaceous particles (pollen, spores, plant fragments) (Genga et al., 2018). Repeated analyses performed on single species show the possibility to identify the presence of polluting elements on pollen grains (Mousavi et al., 2019). Here we used the elemental composition-previously defined on different reference pollen taxa-as a proxy for total pollen-like particle identification, together with size and shape filter criteria. This approach could be further implemented in order to verify the possibility of a more specific pollen identification.

Overall, the land use of the study area has to be considered for the interpretation of the obtained results. The following description is focused on a $5-\mathrm{km}$ radius area surrounding the aerobiological site of San Michele all'Adige because at larger distances the local topography drastically changes to mountainous, and consequently the land use changes. Anyway, it is well known that pollen can travel larger distances, and it is conceivable that also pollen grains coming from further away are sampled. The 5-km radius area surrounding the aerobiological site of San Michele all'Adige shows a quite small fraction (8.4\%) covered by artificial surface (urban fabrics and industrial or commercial units); besides this, one of the likely most important source of anthropogenic particulate is the highly transited highway that crosses the area from north-east to south-east, and lies about $1 \mathrm{~km}$ away from the sampling site. The largest part (ca. 90\%) of the 5-km radius area results to be covered by vegetation, both (semi-)natural and cultivated, with the presence of several wind-pollinated tree, shrub and herb species (Cristofori et al., 2010). This implies that, mostly in springtime, a high load of pollen is released in the atmosphere being the main source of the 20-40 $\mu \mathrm{m}$ and partially to the 10-20 $\mu \mathrm{m}$ and $40-80 \mu \mathrm{m}$ fractions of bright particles (i.e., those of natural origin). Thus, in this case, the peculiar local land use characteristics (i.e., densely vegetated area) may have partially contributed to the positive results obtained by automated $\mathrm{OM}$, that filtered the pollen-candidate fraction on the basis of particle grey value and size. The automated SEM/EDX analysis with the implementation of more specific filtering criteria based on the particle size, shape and chemical composition, allowed an even more precise screening of the pollen-like particles. We must therefore take into account that results obtained by automated $\mathrm{OM}$ for the pollen fraction identification can be site-dependent, even if obtainable quite fast, while those obtained from the single-particle SEM/EDX analysis, followed by data processing of the morpho-chemical information, are more precise and site-independent, but also more timeconsuming. Further studies in a wider range of different environments such as highly anthropized urban areas with low vegetation cover, parks and forested areas almost totally covered by vegetation, and remote high-elevation sites with no or negligible presence of local vegetation, could be of interest for testing a larger applicability of the morpho-chemical proxies adopted in this study for identifying pollen-like particles. Besides, the automated OM approach could be further implemented using specific staining for pollen, allowing a more precise filtering criterion. Both automated analytical approaches (OM and SEM/EDX), even if tested only on passively collected samples in this study, could be applied on particles collected with other devices, including the Hirst-type sampler.

The option of performing the analysis of biogenic single particles alongside with the anthropogenic ones is an interesting perspective that may render possible to simultaneously characterize the chemical and the biological air quality (Bogawski et al., 2016; Grewling et al., 2019). Usually the airborne coarse particles with diameter larger than $10 \mu \mathrm{m}$ are not considered in the routine air quality monitoring. However, this particle fraction has a crucial importance since it contains the biological fraction represented by pollen and spores, responsible-among others-of respiratory allergies, and human and plant diseases; in addition, coarse particles concur, together with the fine ones, to important ecosystem processes, e.g., influencing the radiative properties of the atmosphere, inducing the nucleation and playing a key role in biogeochemistry of soils (Gieré and Querol, 2010). The concurrent availability of chemical and biological data on air quality is considered useful also for epidemiological studies and policies, allowing an integrated approach (Robichaud, 2020).

Airborne anthropogenic as well as biogenic (e.g., allergenic pollen and spore) particles are usually analyzed by means of specific active samplers mostly located in urban centers. Thus, very few data are available for rural, remote, mountainous areas. Passive sampling together with automated analytical approaches could be an effective option to overcome the constraints of costs and 
electricity need posed by the active sampling, allowing to perform a source-differentiated monitoring also in usually uncovered areas, and concurrently simplifying the analysis of airborne particles.

\section{CONCLUSIONS}

Our results prove passive sampling to be a feasible alternative to active volumetric sampling in aerobiological monitoring. Additionally, our fully automated analysis, which was based on optical and scanning electron microscopy, accurately identified the pollen fraction in the passive sampling specimens. Intense, large-scale and/or long-term studies conducted in remote or orographically complex areas-locations typically excluded during routine air quality monitoring-can apply our methods to easily obtain reliable data on airborne particulate matter, e.g., pollen.

\section{ACKNOWLEDGMENTS}

We are grateful to Maria Cristina Viola for her help in the analysis of aerobiological samples by manual optical microscopy. We thank the reviewers and editor for the constructive suggestions to improve the quality of the manuscript.

\section{DISCLAIMER}

This research did not receive any specific grant from funding agencies in the public, commercial, or not-for-profit sectors.

\section{SUPPLEMENTARY MATERIAL}

Supplementary material for this article can be found in the online version at https://doi. org/10.4209/aaqr.210010

\section{REFERENCES}

Abràmoff, M.D., Magalhaes, P.J., Ram, S.J. (2004). Image processing with ImageJ. Biophotonics Int. 11, 36-42. https://imagescience.org/meijering/publications/download/bio2004.pdf (accessed June 2021).

Alcazar, P., Galan, C., Carinanos, P., Dominguez-Vilches, E. (1999). Effects of sampling height and climatic conditions in aerobiological studies. J. Investig. Allergol. Clin. Immunol. 9, 253-261.

Bogawski, P., Grewling, L., Fratczak, A. (2016). Flowering phenology and potential pollen emission of three Artemisia species in relation to airborne pollen data in Poznań (Western Poland). Aerobiologia 32, 265-276. https://doi.org/10.1007/s10453-015-9397-z

Cristofolini, F., Anelli, P., Billi, B.M., Bocchi, C., Borney, M.F., Bucher, E., Cassoni, F., Coli, S., De Gironimo, V., Gottardini, E., Martinet, N., Miraglia, A., Para, C., Rossi, M., Tassan-Mazzocco, F., Travaglini, A., Verardo, P., Marchesi, S. (2020). Temporal trends in airborne pollen seasonality: Evidence from the Italian POLLnet network data. Aerobiologia 36, 63-70. https://doi.org/10.10 07/s10453-019-09609-8

Cristofori, A., Cristofolini, F., Gottardini, E. (2010). Twenty years of aerobiological monitoring in Trentino (Italy): assessment and evaluation of airborne pollen variability. Aerobiologia 26, 253-261. https://doi.org/10.1007/s10453-010-9161-3

D’Amato, G., Spieksma, F.Th.M., Bonini, S. (1991). Allergenic pollens and pollinosis in Europe. Wiley-Blackwell.

Damialis, A., Traidl-Hoffmann, C., Treudler, R. (2019). Climate Change and Pollen Allergies. in: Marselle, M., Stadler, J., Korn, H., Irvine, K., Bonn, A. (Eds.), Biodiversity and Health in the Face of Climate Change. Springer.

Faegri, K., Iversen, J. (1989). Textbook of pollen analysis. John Wiley and Sons, Chichester. 
Fernandez-Llamazares, A., Belmonte, J., Boada, M., Fraixedas, S. (2014). Airborne pollen records and their potential applications to the conservation of biodiversity. Aerobiologia 30, 111-122. https://doi.org/10.1007/s10453-013-9320-4

Gieré, R., Querol, X. (2010). Solid Particulate Matter in the Atmosphere. Elements. 6, 215-222. DOI: 10.2113/gselements.6.4.215

Grewling, L., Fratczak, A., Kostecki, L., Nowak, M., Szymanska, A., Bogawski, P. (2019). Biological and chemical air pollutants in an urban area of central Europe: Co-exposure assessment. Aerosol Air Qual. Res. 19, 1526-1537. https://doi.org/10.4209/aaqr.2018.10.0365

Halbritter, H. (1998). Preparing living pollen material for scanning electron microscopy using 2, 2-dimethoxypropane (DMP) and critical-point drying. Biotech. Histochem. 73, 137-143. https://doi.org/10.3109/10520299809140519

Hirst, J.M. (1952). An automatic volumetric spore trap. Ann. Appl. Biol. 39, 257-265. https://doi.org/10.1111/j.1744-7348.1952.tb00904.x

Hyde, P., Mahalov, A. (2020). Contribution of bioaerosols to airborne particulate matter. J. Air Waste Manage. Assoc. 70, 71-77. https://doi.org/10.1080/10962247.2019.1629360

Kenđel, A., Zimmermann, B. (2020). Chemical analysis of pollen by FT-Raman and FTIR spectroscopies. Front. Plant Sci. 11, 352. https://doi.org/10.3389/fpls.2020.00352

Lagerstrom, R., Holt, K., Arzhaeva, Y., Bischof, L., Haberle, S., Hopf, F., Lovell, D. (2015). Pollen image classification using the Classifynder system: Algorithm comparison and a case study on New Zealand honey. Adv. Exp. Med. Biol. 823, 207-226. https://doi.org/10.1007/978-3-31910984-8_12

Leontidou, K., Vernesi, C., De Groeve, J., Cristofolini, F., Vokou, D., Cristofori, A. (2018). DNA metabarcoding of airborne pollen: New protocols for improved taxonomic identification of environmental samples. Aerobiologia 34, 63-74. https://doi.org/10.1007/s10453-017-9497-z

Mandrioli, P., Comtois, P., Levizzani, V. (1998). Methods in Aerobiology. Pitagora Editrice S.r.l., Bologna.

Martorano, L., Erwin, E.A. (2018). Aeroallergen exposure and spread in the modern era. J. Allergy Clin. Immunol. Pract. 6, 1835-1844. https://doi.org/10.1016/j.jaip.2018.08.014

Meier, M.F., Mildenberger, T., Locher, R., Rausch, J., Zund, T., Neururer, C., Ruckstuhl, A., Grobety, B. (2018). A model based two-stage classifier for airborne particles analyzed with Computer Controlled Scanning Electron Microscopy. J. Aerosol Sci. 123, 1-16. https://doi.org/ 10.1016/j.jaerosci.2018.05.012

Miki, K., Kawashima, S., Clot, B., Nakamura, K. (2019). Comparative efficiency of airborne pollen concentration evaluation in two pollen sampler designs related to impaction and changes in internal wind speed. Atmos. Environ. 203, 18-27. https://doi.org/10.1016/j.atmosenv.2019.0 1.039

Mondol, A.S., Patel, M.D., Ruger, J., Stiebing, C., Kleiber, A., Henkel, T., Popp, J., Schie, I.W. (2019). Application of high-throughput screening Raman spectroscopy (HTS-RS) for label-free identification and molecular characterization of Pollen. Sensors 19, 4428. https://doi.org/10.3 390/s19204428

Mousavi, F., Shahali, Y., Pourpak, Z., Majd, A., Ghahremaninejad, F. (2019). Year-to-year variation of the elemental and allergenic contents of Ailanthus altissima pollen grains: An allergomic study. Environ. Monit. Assess. 191, 362. https://doi.org/10.1007/s10661-019-7458-4

Norra, S., Yu, Y., Dietze, V., Schleicher, N., Fricker, M., Kaminski, U., Chen, Y., Stuben, D., Cen, K. (2016). Seasonal dynamics of coarse atmospheric particulate matter between $2.5 \mu \mathrm{m}$ and 80 $\mu \mathrm{m}$ in Beijing and the impact of 2008 Olympic Games. Atmos. Environ. 124, 109-118. https://doi.org/10.1016/j.atmosenv.2015.08.029

Nunez, A., Moreno, D.A. (2020). The differential vertical distribution of the airborne biological particles reveals an atmospheric reservoir of microbial pathogens and aeroallergens. Microb. Ecol. 80, 322-333. https://doi.org/10.1007/s00248-020-01505-w

Oteros, J., Pusch, G., Weichenmeier, I., Heimann, U., Moller, R., Roseler, S., Traidl-Hoffmann, C., Schmidt-Weber, C., Buters, J.T.M. (2015). Automatic and online pollen monitoring. Int. Arch. Allergy Immunol. 167, 158-166. https://doi.org/10.1159/000436968

Oteros, J., Weber, A., Kutzora, S., Rojo, J., Heinze, S., Herr, C., Gebauer, R., Schmidt-Weber, C.B., Buters, J.T.M. (2020). An operational robotic pollen monitoring network based on automatic image recognition. Environ. Res. 191, 110031. https://doi.org/10.1016/j.envres.2020.110031 
Robichaud, A. (2020). An overview of selected emerging outdoor airborne pollutants and air quality issues: The need to reduce uncertainty about environmental and human impacts. J. Air Waste Manag. Assoc. 70, 341-378. https://doi.org/10.1080/10962247.2020.1723738

Rojo, J., Nunez, A., Lara, B., Sanchez-Parra, B., Moreno, D.A., Perez-Badia, R. (2019). Comprehensive analysis of different adhesives in aerobiological sampling using optical microscopy and highthroughput DNA sequencing. J. Environ. Manage. 240, 441-450. https://doi.org/10.1016/j.jen vman.2019.03.116

Sauvageat, E., Zeder, Y., Auderset, K., Calpini, B., Clot, B., Crouzy, B., Konzelmann, T., Lieberherr, G., Tummon, F., Vasilatou, K. (2020). Real-time pollen monitoring using digital holography. Atmos. Meas. Tech. 13, 1539-1550. https://doi.org/10.5194/amt-13-1539-2020

Schneider, C.A., Rasband, W.S., Eliceiri, K.W. (2012). NIH Image to ImageJ: 25 years of image analysis. Nat. Methods 9, 671-675. https://doi.org/10.1038/nmeth.2089

Sommer, F., Dietze, V., Baum, A., Sauer, J., Gilge, S., Maschowski, C., Giere, R. (2018). Tire abrasion as a major source of microplastics in the environment. Aerosol Air Qual. Res. 18, 2014-2028. https://doi.org/10.4209/aaqr.2018.03.0099

Stillman, E.C., Flenley, J.R. (1996). The needs and prospects for automation in palynology. Quat. Sci. Rev. 15, 1-5. https://doi.org/10.1016/0277-3791(95)00076-3

Tian, Z.X., Dietze, V., Sommer, F., Baum, A., Kaminski, U., Sauer, J., Maschowski, C., Stille, P., Cen, K., Giere, R. (2017). Coarse-particle passive-sampler measurements and single-particle analysis by transmitted light microscopy at highly frequented motorways. Aerosol Air Qual. Res. 17, 1939-1953. https://doi.org/10.4209/aaqr.2017.02.0064

UNI EN16868:2019. Ambient air - Sampling and analysis of airbone pollen grains and fungal spores for networks related to allergy - Volumetric Hirst method. ICS: 13.040.20.

VDI 2119 (2013). Ambient air measurements. Sampling of atmospheric particles $>2.5 \mu \mathrm{m}$ on an acceptor surface using the Sigma-2 passive sampler. Characterization by optical microscopy and calculation of number settling rate and mass concentration. ICS: 13.040.01. Beuth Verlag, Berlin, Germany.

VDI 4330 (2007). Monitoring the effects of genetically modified organisms (GMO) - Pollen monitoring - Technical pollen sampling using pollen mass filter (PMF) and Sigma-2 sampler. ICS: 13.020.99. Beuth Verlag, Berlin, Germany.

Velasco-Jimenez, M.J., Alcazar, P., de la Guardia, C.D., Trigo, M.M, de Linares, C., Recio, M., Galán, C. (2020). Pollen season trends in winter flowering trees in South Spain. Aerobiologia 36, 213224. https://doi.org/10.1007/s10453-019-09622-X

Waza, A., Schneiders, K., May, J., Rodríguez, S., Epple, B., Kandler, K. (2019). Field comparison of dry deposition samplers for collection of atmospheric mineral dust: Results from single-particle characterization. Atmos. Meas. Tech. 12, 6647-6665. https://doi.org/10.5194/amt-12-66472019 